\title{
Concern, pressure and lack of knowledge affect choice of not wanting to know high-risk status
}

\author{
Ulrica Swartling ${ }^{\star,}$, Stefan Eriksson ${ }^{2}$, Johnny Ludvigsson $^{1}$ and Gert Helgesson ${ }^{2}$
}

\author{
${ }^{1}$ Division of Paediatrics and Diabetes Research Centre, Faculty of Health Sciences, Department of Molecular and \\ Clinical Medicine, Linköping University, Linköping, Sweden; ${ }^{2}$ Centre for Bioethics at the Karolinska Institutet and \\ Uppsala University, Uppsala, Sweden
}

The 'right not to know' one's genetic status has been increasingly more recognised in ethical and legal instruments. Yet empirical research is limited, leaving discussion on a theoretical level. There are also divergent ideas as to what extent it should be respected. In this study, we explored the clinical preconditions for disclosure of increased risk of getting diabetes in children. We included questions in the clinical 5-year questionnaire of a predictive screening for the risk of type 1 diabetes (T1DM), asking the respondents $(n=7206)$ whether they wished to be informed of their children's potential risk status. The group of $2 \%$ of the respondents who did not want to know about risk status proved to be significantly associated to concern with natural history data (OR 4.03), lack of knowledge (OR 3.17), pressure to participate (OR 2.99) and the child's disease development (OR 2.18). We discuss whether parents'/ participants' 'no' to high-risk information may call for a more nuanced response such as information and support, rather than simply respect their wish not to know. We furthermore argue that it is ethically questionable whether the parents' expressed wish not to know should prima facie override the potential benefits for their child. We conclude that this constitutes sufficient reason not to promote a default solution where people's expressed wishes not to know are taken at face value.

European Journal of Human Genetics (2007) 14, 556-562. doi:10.1038/sj.ejhg.5201786; published online 21 February 2007

Keywords: ethics; screening; right not to know; type 1 diabetes

\section{Introduction}

The trend in ethics policy is to promote the view that people have the right to decide for themselves whether or not they wish to be informed about, for example, genetic high-risk status. The Universal Declaration on the Human Genome and Human Rights, issued by the UNESCO in 1997, says in Article 5 (c) that 'The right of each individual to decide whether or not to be informed about the results of genetic examination ... should be

\footnotetext{
${ }^{*}$ Correspondence: Dr U Swartling, Division of Paediatrics and Diabetes Research Centre, Department of Molecular and Clinical Medicine, Faculty of Health Sciences, Linköping University, Linköping 581 85, Sweden. Tel: + 4613 223147; Fax: + 4613 148265;

E-mail: ulrgu@imk.liu.se or ulrica.swartling@imk.liu.se All authors have seen and approved the final version. Received 30 August 2006; revised 23 November 2006; accepted 5 January 2007; published online 21 February 2007
}

respected'. ${ }^{1}$ The WHO and the Council of Europe also recognise the right to remain in ignorance: 'the wish of individuals and families not to know genetic information, including test results, should be respected', and 'Everyone is entitled to know any information collected about his or her health. However, the wishes of individuals not to be so informed shall be observed'. ${ }^{2-3}$ Other documents stating this have been issued by the Nuffield Council on Bioethics, the Council of Europe, the World Medical Association, and the British Medical Association. $^{4-7}$

From the formal language used in some of the ethical and legal instruments, researchers may well draw the conclusion that it implies an entitlement or absolute right that overrides other claims or interests involved. However, it must be questioned whether this was, or should have been, the intention of policy makers. 
In the bioethical debate, it is widely agreed that individuals may have a legitimate interest in not wanting to know certain facts about their personal health such as their genetic status, the idea being that if there is an indication that an individual does not wish to know, then this wish should be respected by others, unless there is risk of harm to third parties. In such cases, disclosure may be ethically justified. ${ }^{8-11}$ Although this 'interest' or 'right' is originally modelled from the idea of an autonomous individual who decides upon matters important to his or her own health, ${ }^{12}$ it is also often claimed to be justified from the viewpoint of the right to a private sphere. ${ }^{13-15}$

When discussing the right not to know there are two important points to consider. First, the notion of a right or interest in not knowing is mainly discussed in relation to situations involving individuals - examples given usually concern predisposition or carrier tests. While acknowledging the importance of such contexts, we must also remember that genetic and other high-risk information also occurs in other clinical contexts, for example, largescale population screening and predictive screening for disease markers. Those contexts usually involve the inclusion of whole families, including children (who have legitimate interests/developing agency even though they have a limited autonomy). ${ }^{16-20}$ Today such considerations have led to a dawning realisation since we might have obligations to disclose information to biological relatives, that we live in social relationships that make moral demands on us. To care for those whom we feel responsible for might often presuppose that we share the information we have, something that goes against the emphasis on a right not to know. We therefore need to think again about the values we find important when involving people in research, not least about the right not to know. ${ }^{21-24}$

Second, the comparative lack in some ethical guidelines and reports of a discussion regarding how interests should be balanced might be explained by the absence of empirical data, which has led to the predominant use of hypothetical situations with hypothetical persons. In order to properly evaluate the moral significance of a presumed 'right', 'wish' or 'interest' not to know one's genetic or other high-risk status, we need to know more about the empirical base, about what motives people have for such wishes or choices, especially since the research contexts where such decisions are made are increasingly diverse. This article begins to address this need for data.

As disclosure of high risk is a precondition for obtaining informed consent to potential future high-risk follow-up, we asked participants beforehand about their attitude towards being informed in case their child would belong to the high-risk group. The clinical study cohort consisted of 7206 families in their fifth year of participation in the ABIS study (All Babies in South-East Sweden), a longitudinal predictive screening for type 1 diabetes (T1DM). Two percent $(n=142)$ of the respondents reported that they did not want to know, regardless of whether any intervention or prevention measures were available. In this paper, we explore this group further. This study is part of a larger multi-disciplinary project aiming to analyse and suggest criteria for information, consent and disclosure issues in Swedish longitudinal medical research involving children.

\section{Methods}

The data used in this paper originates from ABIS (All Babies in Southeast Sweden), a longitudinal predictive screening for risk of T1DM and its association to environmental factors, which has followed a large birth cohort since $1997(n=17055) .^{25-26}$ Clinical data have been collected through diary, extensive questionnaires (at birth, 1 year, 2.5-3 years, and 5-6 years) and biological samples (cord and capillary blood, hair, stool, saliva, urine). The questionnaires contained questions concerning medical history, nutrition, demographic background, environmental issues, psychosocial history/psychological variables, including bioethical issues, that is, a comprehensive survey regarding the family including the child's, natural history.

Children with increased risk (and thus eligible for followup studies) are identified by family history of T1DM, diabetes-associated HLA genotypes, and positivity for combinations of diabetes-related autoantibodies (IA-2, $\mathrm{GAD}$, and IAA). Since recent research has revealed development of T1DM in individuals with a protective genotype, each of the three predictors for high risk may be of interest for follow-up studies. ${ }^{27-29}$

At 2.5 years, 531 children in the study cohort were positive for either GAD or IA-2, and 33 children were positive for both GAD and IA-2 (>95th percentile). Over $9 \%$ of these 531 children had a T1DM family history. At 5 years, 415 of the children were positive for one of the two. Sixteen were double positive ( $>90$ th percentile).

During the prospective phase (1997-2005) the research design included non-disclosure. As research currently has led to the identification of preliminary risk groups, the participants were asked in the clinical questionnaire about their view on disclosing the child's risk status. While $98 \%$ of the respondent families wished to be informed about potential high-risk status, $2 \%$ of the respondents $(n=142)$ did not.

Of the 142 families that did not want to know, nine (6.3\%) had a first generation family history of T1DM, six had children with increased risk at 2.5 years based on being positive for autoantibodies (GAD). At 5 years, eight of the 142 families had children double positive for GAD/IA-2 (>90th percentile), two with increased risk through both family history and GAD.

The 5-year extensive clinical questionnaire contains 180 questions accounting for the families' natural history of the past 2.5-3 years. To assess the preconditions of 
disclosure and follow-up of high-risk families the question 'Do you wish to be informed if your child is identified as having high risk of developing T1DM?' was incorporated in the clinical questionnaire. Three alternatives were given (total $n=7206$ ):

1. No, I/we do not want to be informed $(2.0 \%, n=142)$.

2. Yes, I/we want to be informed if there is an effective prevention/intervention measure $(24.1 \%, n=1736)$.

3. Yes, I/we want to be informed regardless of any available intervention/prevention $(73.9 \%, n=5328)$.

Potential correlates to the dependent variable were assessed as those being theoretically relevant to highrisk disclosure (disease history, family history of T1DM, demographic background variables, psychosocial variables including socio-economic status, severe life events, research-ethical factors and maternal worries). This study was approved by the ethical committees at Linkoping University and Lund University (Li 03-629; LU 1051-03).

\section{Derived variables}

The majority of answers to the extensive list of questions regarding the families' natural history in the main clinical questionnaire were given at a 6-point Likert scale. For analysis, they were transformed into nominal or ordinal variables. Family history of T1DM was defined as within first-second generation. Birth complications were defined as prenatal complications: caesarean, NICU (Neonatal Intensive Care Unit), premature birth ( $<36$ weeks). The child's disease development was defined as whether the child had developed a serious or chronic disease: T1DM, celiac disease, IBD/Crohn's, uveit/irit, child RA, IBD/ ulcerous colitis, psychiatric or other. Maternal concerns were defined as (a) concern/worry that the child would develop a severe/chronic disease or become seriously ill or (b) concern/worry that the child would become injured or handicapped or develop abnormally. Disease variables were derived from the extensive list of multifactor/genetically linked/other severe or chronic diseases incorporated in the main questionnaire. Parental satisfaction was defined as self-reported estimation of whether they regarded themselves as good parents. Social support and security/ confidence were defined as self-assessed answers to whether they regarded themselves as having support/ confidence/feeling secure enough to give their child a good start, and were used in the analysis as nominal variables (transformed from a 6-point Likert scale).

Severe life events were derived from the answers ('yes' or 'no') to the question 'Have you experienced any severe lifeevent during the past 2.5 years?' Participants were then given options: death of family member/relative, divorce, severe disease/accident, violence, unemployment, other. The variables passive and negative were derived from selfestimated attitudes concerning whether they regarded themselves to be active/passive and negative/positive, respectively, towards ABIS participation. Lack of knowledge was derived from questions in which the respondents were asked to respond to three accurate statements of the basic aims and methods of the ABIS study: variable defined as having two incorrect answers (2), 1 incorrect answer (1), no correct answer (0). A test including all three statements gave similar results: $\chi^{2}=39.093, P<0.001$. Low selfassessed understanding was derived from a question asking them to self-assess their level of understanding of the ABIS study's main aims. Experienced pressure ('yes'/'no') was derived from a question asking them to state whether they had experienced any pressure with regard to their current participation in the longitudinal ABIS-study. Concern was derived from a question about how the respondents feel regarding the information they have previously submitted by writing a 1-year diary and by answering questionnaires (answers on a 6-point Likert scale).

\section{Statistical analysis}

The coding and analysis was conducted using SPSS 11 . The initial aim was to explore potential bivariate correlations through $\chi^{2}$-analysis and independent $t$-tests (displayed in Table 2). Logistic regression models were used to explore predictors and calculate Odds Ratios (OR) (Table 3).

Two sets of logistic regression models were used based on different samples. The first model included both the identified associated variables (Table 1), including potential confounders on the whole sample of 7206 (backward stepwise LR). We generally considered all variables in the 5-year main questionnaire as potential confounders. Owing mainly to the skewed data distribution we then used the main predictors (concern with natural history data, lack of knowledge, experienced pressure to participate, and the child's disease development) in a smaller model including the $2 \%(n=142)$ who do not want information and the larger group of participants who want information regardless of whether preventive measures/interventions are available $(n=5328)$. Before entering the logistic regression calculation we made an additional exploration of potential confounders, in case the data would be more sensitive to potentially important variables with the more stringent dichotomisation of the dependent variable. The second model was run with the 'enter' procedure. The Hosmer and Lemenshow test was used for model validation. Both models had a $P$-value of 0.6 or higher. To avoid mass significance we have generally considered a $P$-value of 0.01 or less as statistically significant.

\section{Results}

Participants characteristics' are shown in Table 1. There were no significant differences between the groups regarding demographic or general background data: maternal age (range 24-54, mean 37.6 years), education, parity, family 
Table 1 Participants characteristics correlated to their attitude towards high-risk information

\begin{tabular}{|c|c|c|c|}
\hline Demographic variables & $\begin{array}{c}\text { Positive } \\
(\mathrm{n}=7064) \\
\mathrm{n}(\%)\end{array}$ & $\begin{array}{l}\text { Negative } \\
(\mathrm{n}=142) \\
\mathrm{n}(\%)\end{array}$ & $P$ \\
\hline $\begin{array}{l}\text { Age (years) } \\
21-30 \\
31-39 \\
>40\end{array}$ & $\begin{array}{c}303(4.3) \\
4492(63.6) \\
2267(32.1)\end{array}$ & $\begin{array}{c}6(4.3) \\
88(61.7) \\
48(34.0)\end{array}$ & NS (0.623) \\
\hline $\begin{array}{l}\text { Education } \\
\text { Primary } \\
\text { Secondary } \\
\text { University/post-secondary }\end{array}$ & $\begin{array}{c}332(4.7) \\
3927(55.6) \\
2804(39.7)\end{array}$ & $\begin{array}{l}11(7.1) \\
75(52.9) \\
56(40.0)\end{array}$ & NS (0.662) \\
\hline $\begin{array}{l}\text { Relationship (present) } \\
\text { Married/living together } \\
\text { Single } \\
\text { Divorce between parents }\end{array}$ & $\begin{array}{c}6611(93.6) \\
452(6.4) \\
692(9.8)\end{array}$ & $\begin{aligned} & 131(92.1) \\
& 11(7.9) \\
& 10(6.6)\end{aligned}$ & NS (0.484) \\
\hline $\begin{array}{l}\text { Parity } \\
1 \text { child }\end{array}$ & $770(10.9)$ & $8(5.9)$ & NS (0.068) \\
\hline $\begin{array}{l}\text { Professional status } \\
\text { Employed } \\
\text { Education/maternity leave } \\
\text { Unemployed } \\
\text { Sick/on sickness benefit }\end{array}$ & $\begin{array}{l}5305(75.3) \\
1307(18.1) \\
190(2.7) \\
275(3.9)\end{array}$ & $\begin{aligned} 106 & (74.3) \\
27 & (19.3) \\
4 & (2.8) \\
5 & (3.6)\end{aligned}$ & \\
\hline $\begin{array}{l}\text { Family history of diabetes } \\
\text { T1DM } \\
\text { T1DM including type } 2\end{array}$ & $\begin{array}{c}685(9.7) \\
1871(26.5)\end{array}$ & $\begin{array}{c}9(6.3) \\
33(23.2)\end{array}$ & $\begin{array}{l}\text { NS (0.219) } \\
\text { NS (0.388) }\end{array}$ \\
\hline
\end{tabular}

relationships, professional status or family history of T1DM. Paternal age yielded a slightly higher mean (39.9, range 24-66).

Two percent $(n=142)$ of respondents stated that they did not want to know whether their child was at high risk of developing diabetes. $24.1 \%(n=1736)$ marked the alternative 'Yes, I/we want to be informed if there is an effective prevention/intervention measure', while the remaining $73.9 \%$ ( $n=5328)$ wished to be informed regardless of any available intervention/prevention. Table 2 report that the group of $2 \%$ was not associated with any of the psychosocial variables incorporated in the clinical main questionnaire: parental satisfaction, social support, feeling secure and confident, experience of any severe life events during the past 2,5 years, maternal concern about the child's disease development or other concerns related to the child's development or childhood/adolescence events.

We found, however, that the negative attitude towards being informed about high-risk status was due to factors associated with regarding oneself as passive, negative, and experiencing concern with participation in the ABIS-study $(\rho<0.001)$, and concern with the natural history data, that is the clinical questionnaire data $(\rho<0.001)$.

In addition, there was also an association with lack of knowledge about the ABIS study $(\rho<0.001)$ and a low level of self-assessed understanding of the ABIS study's aims and methods ( $\rho<0.01)$, as well as some experienced pressure to participate in the study $(\rho<0.001)$.

We included all variables in the first logistic regression analysis (backward stepwise) in order to differentiate among the variables and also to investigate whether any potential confounders existed. The results identified concern with natural history data $(\mathrm{OR}=4.03$; CI: $1.63-9.98$; $\rho<0.001)$, lack of knowledge (OR=3.18; CI: 2.29-6.04; $\rho<0.001)$, experience of pressure (OR $=2.99$; CI: $1.68-$ 5.33; $\rho<0.001)$, and the child's having developed a serious or chronic disease $(\mathrm{OR}=2.18$; $\mathrm{CI}: 1.09-4.34 ; \rho=0.026)$ as the most significantly correlated factors. For the last step, the Hosmer and Lemenshow test was non-significant $\left(\chi^{2}=1.924, \rho=0.750\right)$.

In the second logistic regression model a smaller sample $(n=5470)$ was used, filtering the group of participants stating that they want to be informed only if some intervention or prevention exists $(n=1736)$. The result yielded odds ratios for lack of knowledge $(\mathrm{OR}=3.82$; $\mathrm{CI}$ : $2.39-6.08 ; \rho<0.001)$, experienced pressure $(\mathrm{OR}=2.54$; CI: $1.41-4.59 ; \rho=0.002)$, the child's development of a severe or chronic disease $(\mathrm{OR}=2.63 ; \mathrm{CI}: 1.34-5.14 ; \rho=0.005)$ and for concern with natural history data $(\mathrm{OR}=2.18$; $\mathrm{CI}$ : $1.04-$ 4.56; $\rho=0.038)$.

\section{Discussion}

Although widely defended, the view that there is a legitimate general right not to know is controversial. This paper presents survey data on the attitude of more than 7200 participants regarding information about their children's potential risk status in the context of a specific longitudinal cohort screening. While the majority were positive towards disclosing information, two percent of the study population stated that they did not want to be informed regardless of whether a prevention or intervention was available. Statistical analysis shows that this group is significantly associated with having ill children, having a negative attitude towards the study in which they participate, dissatisfaction with information, low selfassessed understanding, lack of knowledge of the study, concern with research data, and having experienced pressure to participate. The logistic regression model identified four of these as primary factors: concern with questionnaire data, factual lack of knowledge, experience of pressure to participate, and having children with a prominent disease history.

The data presented here provide reason to doubt that expressed preferences for not wanting information are autonomous. Those who do not want to know regardless of what can be done are strongly associated with factors indicating that they are driven by fear and ignorance; they lack knowledge and show concern with the extensive environmental data they provide, and their child has also, to a significant degree, been more ill than the children of 
Table 2 Main bivariate correlations between position of not wanting high-risk information and potential associated factors $(n=142)$

\begin{tabular}{|c|c|c|c|}
\hline Variables/potential confounders & $\chi^{2}$ value & $d f$ & Sig (value) \\
\hline \multicolumn{4}{|l|}{ Child related factors } \\
\hline Birth complications & 107 & 1 & NS $(0.744)^{*}$ \\
\hline Disease development & 6.963 & 2 & $P<0.05$ \\
\hline Maternal concern (disease/severe illness) & 1.447 & 1 & NS (0.229) \\
\hline Maternal concern (other) & 0.002 & 1 & NS $(0.886)$ \\
\hline \multicolumn{4}{|l|}{ Health related factors } \\
\hline Mother's perceived health & 1.998 & 1 & NS $(0.212)$ \\
\hline Disease in near family & 1.709 & 1 & NS $(0.202)^{\star}$ \\
\hline Disease in extended family (second-third generation) & 0.364 & 1 & NS $(0.070)$ \\
\hline \multicolumn{4}{|l|}{ Psychosocial factors } \\
\hline Parental satisfaction & 7.920 & 4 & NS $(0.095)$ \\
\hline Support & 2.121 & 1 & NS $(0.184)^{\star}$ \\
\hline Security/confidence & 0.072 & 1 & NS (0.789) \\
\hline Experience of severe life-event & 0.088 & 1 & NS $(0.788)^{*}$ \\
\hline \multicolumn{4}{|l|}{ Clinical research related factors } \\
\hline Passive & 19.897 & 1 & $P<0.001$ \\
\hline Negative & 11.364 & 1 & $P<0.01$ \\
\hline Concern/worry (attitude towards participation) & 13.445 & 1 & $P<0.001$ \\
\hline Concern/worry (biological samples) & 1.928 & 1 & NS (0.165) \\
\hline Concern/worry (natural history data) & 11.081 & 1 & $P<0.001$ \\
\hline \multicolumn{4}{|l|}{ Research ethics related factors } \\
\hline Lack of knowledge & 40.337 & 1 & $P<0.001$ \\
\hline Low self-assessed understanding & 8.377 & 1 & $P<0.01$ \\
\hline Experienced pressure to participate & 18.380 & 1 & $P<0.001$ \\
\hline
\end{tabular}

Student $t$-test, *Fischer's.

Table 3 Logistic regression models

\begin{tabular}{|c|c|c|c|c|c|}
\hline Regression models & Samples & Variables & $O R(\operatorname{Exp} B)$ & Cl: Low-Upp (95\%) & Sig. (P-value) \\
\hline Model 2 (entered on step) & $142+5328$ & $\begin{array}{l}\text { (2) Lack of knowledge } \\
\text { (3) Experienced pressure } \\
\text { (4) Child developed chronic/serious disease } \\
\text { (1) Concern with natural history data }\end{array}$ & $\begin{array}{l}3.82 \\
2.54 \\
2.63 \\
2.18\end{array}$ & $\begin{array}{l}2.39-6.08 \\
1.41-4.59 \\
1.34-5.14 \\
1.04-4.56\end{array}$ & $\begin{array}{l}P<0.001 \\
P=0.002 \\
P=0.05 \\
P=0.038\end{array}$ \\
\hline
\end{tabular}

other participants. Furthermore they have experienced pressure either in their original decision to participate or during the 5 years of participation. Their autonomy in this case can therefore be questioned - they do not conform to the ideal of autonomous agents exercising their rights in a knowledgeable and free manner. To simply respect their wish not to know seems like a poor response to their predicament, rather they seem to be in need of extensive support in order to increase their understanding of the study and to strengthen their autonomy, and to leave the study if they wish.

Disclosure is in many cases a precondition for invitation to follow-up studies. However, informing about high-risk status is problematic since not everyone wants the information (and some only on the prerequisite that an effective intervention is available). On the other hand, withholding such important information is also problematic since many people want to know. A way out of this dilemma is to ask beforehand about people's attitudes towards high-risk information. In this way, the act of asking does not imply that something has already been found, and as such, autonomy can be respected regardless of people's attitudes towards the information. This is the approach we have chosen.

However, as we have seen, it is not obvious how to act on the attitudes expressed since it is not always clear that an 
autonomous view is expressed. It may not be those who are properly informed and sufficiently autonomous who act on their presumed right not to know. Furthermore, assuming that an intervention were available, it is ethically questionable whether the parents expressed wish not to know should prima facie override the potential benefits for their child.

This, we would like to argue, is sufficient reason not to promote a default solution where people's expressed wishes not to know are taken at face value. Participants' 'no' to high-risk information may call for a more nuanced response. It is a complex matter to balance competing interests but this has to be done; to grant a party a principal right not to know would cloud the issues at stake. It might even fail to promote the parents' autonomy.

\section{Limitations}

The results and the analysis rely heavily on self-reported data from the clinical questionnaire. We cannot exclude that some of the answers to the questions incorporated have been either under-reported or over-reported. It must also be recognised that there may be other potential confounders that can contribute to our understanding. Our data suggest the need to be cautious when using concepts like rights and autonomous choice to motivate a particular line of action in research settings such as the ABIS study. More research is needed to clarify the reasons behind declining to know about high-risk status.

\section{Role of the funding source}

The Swedish Research Council and the Swedish Council for Working Life and Social Research have been the main funders for this study. The funders had no role in study design, data collection, data analysis, data interpretation, writing the report or in the decision to submit for publication. The corresponding author had full access to all the data and had the final responsibility to submit for publication.

\section{Acknowledgements}

We are indebted to Olle Eriksson at the Department of Mathematics at Linköping University for statistical advice and guidance. We also acknowledge the aid of the ABIS staff: coordinator Ann-Christine Gilmore-Ellis, Christina Larsson and Iris Franzén. Financial support for this research was generously provided by the Swedish Research Council and the Swedish Council for Working Life and Social Research. We also acknowledge the generous support by the Jerring and Samaritan Foundations.

\section{References}

1 United Nations Educational, Scientific and Cultural Organisation (UNESCO): Universal declaration on the human genome and human rights. UNESCO: Paris, 1997 Available from: http://portal.unesco.org/shs/en/ev.php-URL_ID $=1881 \&$ URL_DO $=$ DO_TOPIC\& URL_SECTION $=201$. html.

2 World Health Organisation (WHO): Proposed international guidelines on ethical issues in medical genetics and genetic services. WHO: Geneva, 1997 Available from: http://whqlibdoc.who.int/hq/ 1998/WHO_HGN_GL_ETH_98.1.pdf.

3 Nuffield Council on Bioethics: Genetic Screening: Ethical Issues. Nuffield Council on Bioethics: London, 1993.

4 Council of Europe: Convention for the protection of human rights and dignity of the human being with regard to the application of biology and medicine: convention on human rights and biomedicine. Council of Europe: Oviedo, 1997 Available from: http://conventions.coe.int/treaty/en/Treaties/Html/164.htm.

5 World Medical Association (WMA): World medical association declaration on the rights of the patient. World Medical Association: Lisbon, 1981 Available from: http://www.wma.net/e/policy/ 14.htm.

6 British Medical Association (BMA): Human genetics. Choice and responsibility. Oxford University Press: Oxford, 1998.

7 Council of Europe: Explanatory Report to Convention for the protection of human rights and dignity of the human being with regard to the application of biology and medicine: Convention on Human Rights and Biomedicine. Council of Europe: Strasbourg, 1997.

8 Chadwick R, Levitt M, Shickle D (eds): The right to know and the right not to know. Aldershot, Ashgate, 1997.

9 Romeo-Casabona CM: Human rights issues in research on medical genetics; in: Council of Europe: Ethics and Human Genetics. Council of Europe Editions: Strasbourg, 1994, pp 167-174.

10 Laurie G: In defence of ignorance: genetic information and the right not to know. Eur J Health Law 1999; 6: 119-132.

11 Laurie G: Protecting and promoting privacy in an uncertain world: further defences of ignorance and the right not to know. Eur Jour Health Law 2000; 7: 185-191.

12 Beauchamp TL, Childress JF: Principles of Biomedical Ethics, 5th ed. Oxford University Press: New York, 2001.

13 Andorno R: The right not to know: an autonomy based approach. J Med Ethics 2004; 30: 435-439.

14 Laurie G: Genetic privacy. A challenge to medico-legal norms. Cambridge University Press: Cambridge, 2002.

15 Harris J, Keywood K: Ignorance, information and autonomy. Theor Med Bioeth 2001; 22: 415-436.

16 Miller RB: Children, Ethics, and Modern Medicine. Indiana University Press: Bloomington, 2003.

17 Wendler D, Shah S: Should children decide whether they are enrolled in nonbeneficial research? Am J Bioeth 2003; 3 (4): 1-7.

18 Joffe S: Rethink 'affirmative agreement', but abandon 'assent'. Am J Bioeth 2003; 3 (4): 37-38.

19 Rossi WC, Reynolds W, Nelson RM: Assent and parental permission in pediatric research. Theor Med Bioeth 2003; 24: $131-148$.

20 Sen A: Development as freedom. Oxford University Press: Oxford, 1999.

21 Eriksson S: Should results from genetic research be returned to research subjects and their biological relatives? TRAMES - AJ Humanit Soc Sci 2004; 8: 46-62.

22 Finkler K, Skrzynia C, Evans JP: The New genetics and its consequences for family, kinship, medicine and medical genetics. Soc Sci Med 2003; 57: 403-412.

23 Hardwig J: What about the family - the role of family interests in medical decision making. Hastings Cent Rep 1990; 20 (March/ April): 5-10.

24 Kegley JAK: Genetic information and genetic essentialism: will we betray science, the individual, and the community?; In: Kegley JAK (ed): Genetic Knowledge. Human Values \& Responsibility. ICUS: Lexington, Kentucky, 1998, pp 41-66.

25 Gustafsson Stolt U, Ludvigsson J, Liss P-E, Svensson T: Bioethica theory and practice in genetic screening for pre-diabetes. Med Health Care Philos 2003; 6: 45-50. 
26 Gustafsson Stolt U, Helgesson G, Liss P-E, Svensson T, Ludvigsson $\mathrm{J}$ : Information and informed consent in a longitudinal screening involving children: a questionnaire survey. Eur J Hum Genet 2004; 13: 376-383.

27 Scofield RH: Autoantibodies as predictors of disease. Lancet 2004; 363: $1544-1546$.
28 Rich SS, Concannon P: Challenges and strategies for investigating the genetic complexity of common human diseases. Diabetes 2002; 51: 288-294.

29 Harrison LC: Risk assessment, prediction and prevention of type 1 diabetes. Pediatr Diabetes 2001; 2: 71-82. 